DOI: $10.17805 / z p u .2016 .2 .11$

\title{
Повторяющиеся культурные микротексты: диахронный и синхронный аспекты
}

\author{
Н. А. ЗАВьяЛОВА \\ (УРАЛЬСКИЙ ФЕДЕРАЛЬНЫЙ УНИВЕРСИТЕТ \\ ИМ. ПЕРВОГО ПРЕЗИДЕНТА РОССИИ Б. Н. ЕЛЬЦИНА, Г. ЕКАТЕРИНБУРГ)
}

В статье представлены результаты исследовательской программы по изучению повторяемых культурных микротекстов. Автор анализирует явления, традиционно рассматриваемые в современной науке о языке. Лингвистика так и не смогла сформулировать строгих категориальных признаков, по которым анализируемое явление представляется возможным отграничить от смежных явлений. Автор предпринимает попытку сформулировать категориальные признаки анализируемых явлений в рамках философии культуры. Теоретикометодологическая основа исследования заложена в работах: Ю. М. Лотмана, Вал. А. Лукова, Вл. А. Лукова.

Повторяемые культурные микротексты отграничиваются от текстов лингвистических по принципу сверхорганизации культурных смыслов (по Ю. М. Лотману), а также на основании критерия частотности, многократной воспроизводимости в устной и письменной формах. Анализируемые микротексты являются продуктами механизма повтора, лежащего в основе онтофилогенеза и культурогенеза, следовательно, они обнаруживают глубочайшую связь с основами мироздания, которые прослеживаются на разных уровнях: от молекулы ДНК до макроэкономических циклов.

Анализ результатов всероссийских омнибусных социологических опросов, проводимых автором совместно с Центром Ю. Левады (2014, 2016 гг., с общим числом респондентов более 1600 чел.), выявил довольно высокий процент респондентов, использующих данные микротексты в повседневной коммуникации. Анализируемые микротексты можно рассматривать также сквозь призму теории М. Мид в моделях культур - постфигуративной и префигуративной. Они активно востребованы в постмодернистских игровых техниках, что делает их важнейшим элементом современной электронной коммуникации и массовой культуры. Теоретические положения проиллюстрированы многочисленными примерами из сообщений СМИ, электронных изданий, а также рекламных текстов.

Проведенное исследование позволяет проанализировать представленные явления сквозь призму антропологического, культурфилософского и филологического знания, что свидетельствует о междисциплинарном характере рассматриваемых феноменов. 
Ключевые слова: повтор; копирование; текст; повторяющиеся тексты; тезаурус; тезаурусный подход; социокультурное пространство; культурные микротексты; синхронный; диахронный

\section{ВВЕАЕНИЕ}

3 аконы бытия находятся в центре внимания философии с самых первых этапов ее становления и развития. Одни философы искали основы мироздания в религии, Божественном начале, духовных основаниях бытия, другие - в материальном, физиологическом начале всего сущего, третьи пытались объединить духовные и материальные основания.

Обращаясь к современному состоянию проблемы, на наш взгляд, следует рассматривать бытие в двух измерениях: реальном и виртуальном, информационном. Виртуальная реальность сегодня активно развивается, оказывая огромное влияние на социум. Фокус нашего исследования направлен на явление, которое лежит в основе развития и функционирования мира, однако требует еще более глубокого осмысления в условиях существования обычной жизни и виртуальной реальности. Мы рассуждаем о механизме повтора (копирования) как основополагающем принципе развития всего сущего в мире. В рамках нашего исследования мы анализируем повторы микротекстов культурно-коммуникативных формул. Таковыми являются пословицы, поговорки, крылатые выражения, повторяемые фразы из фильмов и цитаты.

Повторяемые тексты - аллюзии - по-разному воспринимаются в рамках культуры. Протодиакон Русской православной церкви Андрей Кураев указывает на шаблонность Всего культурного, отраженную в аллюзиях разного уровня, от языка театра до языка человеческого общения: «Понимаете, однажды в человеке просыпается жажда подлинности. Ему становится душно в мире культуры, в бесконечных взаимных отражениях образов, аллегорий, взаимных отсылок и цитат, скрытых и явных аллюзий...» (Кураев, 2006: Электронный ресурс). Мы задаемся вопросом: не является ли бегство попыткой выйти за границы всеобщего развития? Осуществим ли данный выход? Почему законы повторов так сильны? Как механизмы повторов осуществляются на разных уровнях: от $А$ НК до массовой культуры в целом?

Цель исследования - проанализировать культурную динамику повторяемых элементов на примере культурных микротекстов в диахронном и синхронном аспектах.

\section{ПОВТОР КАК БАЗОВЫЙ ЭВОАЮЦИОННЫЙ \\ МЕХАНИЗМ}

В качестве подтверждения главенствующей роли повтора в механизме эволюции обратимся к современной генетике. Американский философ Р. Аокинз в своем научно-популярном труде «Рассказ предка. Паломничество к истокам жизни» следующим образом описывает суть механизма передачи генов: «...в отношении эволюции мы располагаем... воспроизводимой информацией, которая претерпела невообразимо большое число случаев копирования и которую, позволив себе небольшую поэтическую вольность, мы можем расценивать как аналог письменного текста. Эти исторические записи с поразительной точностью воспроизводились сотни миллионов раз благодаря тому, что в их основе, как и в основе письменности, лежит самоупорядочивающийся алфавит. Информация АНК передается с потрясающей точностью. Отдельные атомы в ней непрерывно меняются, однако информация, которую они кодируют, копируется в течение миллионов, даже сотен миллионов лет» (Аокинз, 2015: 35). Можно сде- 
лать вывод о том, что механизм повтора (копирования) прочно встроен в основу эволюционного развития живых организмов.

Если осуществить переход на уровень выше - от отдельных особей и видов к популяциям, - то здесь уместно говорить о том, что в исторической перспективе трансляция опыта прошлого в настоящем является универсальным, зачастую безальтернативным механизмом социального развития. В своей знаменитой работе «Смыслы социальной жизни» ( «The Meanings of Social Life: A Cultural Sociology») американский социальный философ Аж. Александер приходит к важнейшему выводу: «Tо the cultural process of coding, weighting, and narrating... what comes before is all important» ${ }^{1}$ (Alexander, 2003: 33; выделено нами. - H. 3.).

Провидческим представляется рассуждение писателя М. Твена о «Законе периодического повторения»: «По Закону периодического повторения все, что произошло однажды, обязательно повторится снова, и снова, и снова. И повторы эти случаются не тогда, когда им вздумается, а через регулярные интервалы, и каждый в свое время, по своему собственному внутреннему закону... Исчезнет ли наша чудная цивилизация? Аа, поскольку все исчезает. Вернется ли она из небытия и начнет жить заново? Аа, так будет. Ведь ничего не происходит такого, что позже не смогло бы повториться. И снова, и снова, и так всегда. На подготовку этой цивилизации потрачено более восьми веков, по прошествии которых она начала бурно разрастаться, и менее чем через век она превратилась в удивительное чудо» (Twain, 1972: 28; перевод наш. - H. 3.).

Переходя от анализа роли повтора из социально-исторической плоскости в экономическую, отметим важнейшие циклы, сформулированные Н. А. Кондратьевым в его концепции 50-летних циклов (Кондратьев, 1989). Согласно данной теории, экономические индикаторы изменяются с определенной цикличностью, указывая при этом на то, что одна фаза экономического развития переходит в новую, повторяя при этом сценарий развития предыдущей фазы.

Фокус нашего исследования направлен на анализ цикличности в сфере культурогенеза. Возможно ли применить закон повторов, обозначить циклы в культурном развитии отдельных народов, наций, стран? Ао какой степени прошлое оказывает влияние на культуру настоящего? Какие единицы культуры подвергаются копированию, подобно коду АНК, способствуя при этом устойчивости культурной общности? Важность ретроспекции для культурогенеза подчеркивает в своих исследованиях российский культуролог В. А. Аелеко: «Настоящее есть постоянно пребывающее прошлое... Аля повседневности характерно наличие дальней временной перспективы, особенно в направлении настоящее - прошлое. Повседневность ретроспективна... Настоящее мыслится как проекция прошлого» (Иелеко, 2002: 80-85).

\section{ПОВТОРЯЕМЫЕ МИКРОТЕКСТЫ КУАЬТУРЫ: АИАХРОННЫЙ АСПЕКТ}

Материалом нашего исследования культурных циклов послужили тексть. Связь текста и культуры мы рассматриваем как связь строевой единицы и целого. Ю. М. Аотман пишет: «...культура представляет собой коллективный интеллект и коллективную память, т. е. надындивидуальный механизм хранения и передачи некоторых сообщений (текстов) и выработки новых. В этом смысле пространство культуры может быть определено как пространство некоторой общей памяти, т. е. пространство, в пределах которого некоторые общие тексты могут сохраняться и быть актуализированы» (Иотман, 1992: 200). Ученый полагает, что в качестве текстов культуры в первую очередь 
следует анализировать пословицы и поговорки, крылатые выражения, так как в них встроены механизмы коллективной надындивидуальной памяти.

Ю. М. Цотман выделяет несколько параметров, по которым следует соотносить текст и культуру. Перечислим наиболее важные: 1) антропоцентричность (человек как творец культуры и ее проявление); 2) диалогический диалогический характер взаимоотношений культуры и текста; 3) семиотичность культуры и текста; 4) символичность; 5) категориальная общность. «Культурная память» текста основывается на ассоциативно-образной сущности текста, при этом текст выполняет функцию «информационного генератора» (там же: 132).

Аля анализа мы привлекаем микротексты: фразеологические обороты, цитаты из книг, кинофильмов, устойчивые выражения. Несмотря на свой относительно малый размер (некоторые выражения состоят всего из двух лексем), мы считаем данные выражения текстами, поскольку для них характерны завершенность, смысловая законченность, связность и стилевое единство.

Остановимся более подробно на понятии «текст» как единицы культуры и соотнесем его с анализируемым материалом. Рассуждая над оппозицией «текст - не текст» в рамках культуры, Ю. М. Аотман говорит о том, что «исходным для культурологического понятия текста является именно тот момент, когда сам факт лингвистической выраженности перестает восприниматься как достаточный для того, чтобы высказывание превратилось в текст» (там же). Ученый указывает на то, что с точки зрения культуры не всякое языковое высказывание является текстом. Каковы параметры текста в рамках культуры? По мнению Ю. М. Аотмана, текстам культуры характерна письменная фиксация, поскольку «не всякое сообеение достойно быть записанным: одновременно все записанное получает особую культурную значимость, превращается в текст» (там же: 134). Однако в дописьменных культурах также существуют особые критерии текстовости, которые ученый определяет следующим образом: «...в устных культурах текстам... приписывается обязательная сверхорганизация в форме пословицы, афоризма с определенными структурными признаками» (там же). Аалее он подчеркивает, что с развитием современных средств массовой коммуникации письменная фиксация вновь становится факультативным признаком культурного текста, а на первое место выходит «сверхъязыковая организация высказывания».

Ключевая идея, лежащая в основе нашей работы, была сформулирована в работе Вал. А. Аукова и Вл. А. Аукова «Тезаурусы II» (Ауков Вал., Ауков Вл., 2013). В рамках данной работы анализируемые единицы рассматриваются как крылатые слова: «Культурные константы имеют свойство облекаться в знаковые формы, из которых особую разновидность составляют крылатые слова, широко используемые в определенном культурном ареале именно как вербальные свидетельства константных скреп культуры. Мы определяем крылатые слова как слова и устойчивые сочетания слов, которые а) выражают обобщенное содержание, применяемое как образец, правило, идея, оценка, и т. п. при характеристике широкого класса явлений, процессов, отношений, свойств и т. п.; б) признаются в рамках тех или иных культур общеизвестными, общепонятными, общезначимыми; в) являются свидетельством определенного уровня культурного развития как тех, кто использует в своей речи (устной или письменной) такие слова и словосочетания, так и тех, кто способен дешифровать эти культурные коды» (там же: 85). Важнейшим свойством данных текстов является их повторяемость, высокая частотность в рамках тезаурусов социокультурного пространства. Это свойство сближает анализируемый материал и с копируемыми участками кода 
АНК, и с «Законом периодического повторения» М. Твена. В психологии аналогичные явления связывают с эффектом привязки (от англ. anchoring, adjustment) (Fombrun, Shanley, 1990), сходным механизмом мы считаем эффект чистой экспозиции (от англ. mere exposure effect), когда знакомая, повторяемая несколько раз информация, музыкальный отрывок воспринимаются как более точные, вызывают симпатию и доверие (Zajonc, 2001). Аанные эффекты легли в основу рекламы, маркетинга, психологии (Reber et all., 1998), (Fang et all., 2007). Экспериментальные данные свидетельствуют о том, что человек восприимчив к повторам уже в перинатальный период (Jacoby, Dallas, 1981). По аналогии с критерием «письменной фиксации» культурных текстов М. Ю. Аотмана критерий повторяемости представляется доводьно надежным, поскольку не всякое высказывание подхватывается большинством, достойно повтора. Повторяемые, копируемые, воспроизводимые тексты более достоверны, так как они выражают состояние сознания не одного человека, а многих людей, индивидуальный автор в данном случае отсутствует, зачастую анализируемые микротексты воспроизводятся целыми поколениями.

\section{ПОВТОРЯЕМЫЕ МИКРОТЕКСТЫ КУАБТУРЫ: СИНХРОННЫЙ АСПЕКТ}

В качестве доказательства социокультурной значимости анализируемого явления для современного российского общества проанализируем данные социологического опроса, проведенного нами совместно с Центром Ю. Цевады в феврале 2014 г. В рамках нашей проблематики мы сформулировали вопрос для омнибусного опроса, проводимого Центром Ю. Аевады. Основным результатом данного опроса является показатель $43,1 \%$ из числа респондентов, согласившихся с тем, что они часто используют в повседневной речи анализируемые типы текстов. В рамках ежемесячного омнибусного опроса сотрудники $\Lambda$ евада-центра обратились к респондентам из 17 регионов России (число опрошенных 1603 чел.) со следующим вопросом: «Часто ли вы пользуетесь в повседневной речи пословицами, поговорками и другими устойчивыми выражениями русского языка, включая в их число цитаты из популярных фильмов/телепередач, высказывания известных политиков/военачальников, а также ненормативную лексику?». Вопрос соединил в себе единицы разных культурных пластов, однако мы считаем возможным постановку вопроса (который в нашей формулировке был включен в анкету) подобным образом в силу культурной гетерогенности самого явления. С одной стороны, мы имеем здесь дело с частотными высокохудожественными выражениями, зафиксированными фольклорными словарями, словарями крылатых слов и выражений. С другой стороны, повседневность постоянно порождает новые выражения, которые в словари не входят, но регулярно воспроизводятся носителями языка, манифестируя тем самым современное состояние общества и культуры. В своих работах мы уже анализировали выражения, не кодифицированные словарями: «сланцевая революция», «Крым наш» (см.: Завьялова, 2015). Обратим внимание на стремительно набирающее популярность выражение «50 оттенков», которое содержит в себе аллюзию на нашумевшие эротическую книгу и фильм, что придает дополнительную пикантность названию, например, бизнес-тренинга Б. Жалило: «50 omтенков “дорого”. Техники предотвращения и преодоления возражений» (Бизнес-тренинг ... : Электронный ресурс).

Мы не анализируем обсценную лексику, просторечия и грубые ругательства. ОАнако не следует отрицать их обильное присутствие в коммуникационном поле современного общества, что по-своему отражает состояние его культуры и нравственно- 
сти. На наш взгляд, особую ценность для философии культуры, составляющей культурный портрет нации, представляют языковые знаки, употребляемые большинством. Ученые указывают на то, что описание повседневного опыта должно базироваться на «индексичных выражениях» (Филмер, 1978: 336), т. е. на тех описаниях, которые создают в ходе повседневности сами ее участники. Антрополог Э. А. Орлова, комментируя обобщения основателя интерпретативной антропологии К. Гирца, подчеркивает важность его мнения о том, что к культуре в целом следует относить компоненты, которые: «традиционны, т. е. формируются в историческом опыте социальной группы и в качестве культурного наследия передаются и осваиваются акторами в процессах социализации и инкультурации, а не конструируются из личного опыта индивида; закодированы в коллективном, а не индивидуальных знаках» (Орлова, 2010: 416). При этом подобные знаки должны не ориентироваться на высоко концептуальную культуру отдельных интеллектуальных элит, что необходимо для анализа нации как совокупности индивидов со средним и низким уровнем интеллекта. Наиболее ярко идею усредненного интеллекта нации выразил в своих размышлениях К. Г. Юнг: «Вы понимаете, что сто самых интеллигентных в мире людей составят вместе тупую толпу? Аесять тысяч таких обладают коллективной интеллигентностью крокодила... Вследствие этого многомиллионная нация являет собой нечто даже нечеловеческое. Это ящерица, или крокодил, или волк» (Юнг, 2010: 254).

Полученные результаты проведенного омнибусного опроса красноречиво свидетельствуют о высокой степени распространения анализируемого явления. Приблизительно каждый второй респондент согласился с тем, что он использует в своей речи устойчивые коммуникативные обороты. Выскажем предположение о том, что респонденты не всегда отдают себе отчет в том, насколько часто пользуются данными формулами, и представленные показатели могут подвергаться корректировке в сторону увеличения доли положительных ответов. Отметим, что наиболее охотно наличие повторяемых оборотов в своей речи признают относительно состоятельные граждане (они ответили, что могут позволить себе приобрести товары длительного пользования) и жители столицы.

Результаты второго опроса, проведенного в феврале 2016 г., свидетельствуют о том, что два года спустя россияне в меньшей степени согласились признать наличие повторяемых оборотов в своей речи. Число отрицательных ответов практически в два раза превосходит ответы «да», но и $37,1 \%$ респондентов - это больше трети опрошенных. Обращает на себя внимание тот факт, что на этот раз наличие повторяемых оборотов в своей речи охотно признали наиболее состоятельные респонденты, которые имеют возможность приобрести автомобиль, а также респонденты старше 55 лет и жители городов, население которых не превышает 100 тыс. человек. Выскажем предположение о том, что в условиях современного экономического кризиса россияне в меньшей степени склонны задумываться о своей речи. И все-таки зададимся вопросом: действительно ли повторяемые обороты - удел пожилых провинциалов, управляющих новеньким собственным автомобилем?

Отрицательно ответим на заявленный вопрос, поскольку контент-анализ социальных сетей и блогов выявляет повышенный интерес к анализируемым микротекстам, авторами которых являются современные молодые люди. Приведем несколько примеров из нашей коллекции. «Круглая сумла на квадратные метры » (рекламный слоган банка «Аемидов»), «Молодым - своя жизнь-площадь. Жилой дом “на Индустрии”» (рекламный слоган программы ипотеки «Газпромбанка»). "Авойной удар: быстрая 
ипотека и снижение иень на квартиру» (рекламный слоган «Газпромбанка»). Броские слоганы легли в основу заголовков книг: «Bыжми из бизнеса все! 200 cпособов повысить продажи и прибыль» (Парабеллум, Мрочковский 2011). "Пан или пропал. Идеология лидера - идеология победь» (название бизнес-тренинга Р. Гандапаса). «В подавляющем большинстве бизнесов продажи представляют собой настоящий черный ящик» (Парабеллум, Мрочковский 2012: 4). "А рынок, такой молодой! И чудный Сургут впереди! » (Афанасьева, 2015: Электронный ресурс), «Возврашение блудного Януковича. Клан быьшего президента Украины ищет возможности для реванша» (Родионов, 2015: Электронный ресурс), «Униженные и оскорбленные современного мира» (Механик, 2015: Электронный ресурс). "Аальний Восток становится ближним» (Аукьянов, 2013а: Электронный ресурс). "ЕВропейщы в поисках своего угла: откуда беретсл стремление жителей ЕС к независимости? " (Аукьянов, 2013b: Электронный ресурс). "Чем бъ дитя ни тешилось...”. Геи выходят на митинг y “Останкино". А все из-за Мамонтова и Челябинского метеорита" (2013: Электронный ресурс).

\section{КУ ИТТУРНЫЕ МИКРОТЕКСТЫ И ПОСТМОАЕРН}

Представленные примеры свидетельствуют о высокой востребованности техники повторения культурных микротекстов в современной коммуникационной культуре. Чем это обусловлено? Господством постмодернистской идеологии в современной коммуникации. Повторяемые микротексты хороши тем, что они идеально подходят для осуществления базовой постмодернистской стратегии - удаления автора.

Теоретик постмодернизма Р. Барт следующим образом описывает данный феномен: «Удаление Автора... это не просто исторический факт или эффект письма: им до основания преображается весь современный текст, или, что то же самое, ныне текст создается и читается таким образом, что автор на всех уровнях его устраняется» (Барт, 1994: 387). Тенденция устранить автора диктует необходимость обращения к культурно-коммуникативным формулам-идиомам, осуществляющим механизмы интертекстуальности. При этом ключевым моментом, актуализованным в культурно-коммуникативных формулах в эпоху постмодерна, является языковая игра: «... говорить значит бороться - в смысле играть; языковые акты показывают общее противоборство (агонистику)» (Ииотар, 1998: 33). Современная языковая игра наделена манящим молодых авторов эффектом coolness, который Ж. Бодрийяр описывает следующим образом: «Coolness - это чистая игра дискурсивных смыслов, подстановок на письме, это непринужденная дистантность игры, которая, по сути, ведется с одними цифрами, знаками и словами, это всемогущество операционной симуляции» (Бодрийяр, 1995: 76). Эффект coolness в рамках анализируемого материала достигается путем интегрирования англосаксонских единиц в исходные русские выражения (Завьялова, 2014).

Отметим, что зачастую мы имеем дело не с единичными примерами повторов микротекстов, а с целыми комплексами со сложной структурой, являющимися фабулой статьи. Обратим внимание на следующий пример, где по аналогии с микротекстом-понятием терминологического характера «человек разумный» образованы новые микротексты: «человек зазаборный», «жилец замкнутый», «горожанин обычный», «житель напуганный». «Новая акция по привлечению внимания к проблемам городской среды получила название “Царь дверей”. И вот ограждения Большого Афанасьевского переулка, Сивцева Вражека и других прилегающих к главной пешеходной улице 
территорий были украшены девятью ироничными табличками: “Человек зазаборный”, “Жилец замкнутый”, “Горожанин обычный”, “Житель напуганный” и т. д.» (Бурлакова, 2013: Электронный ресурс).

Помимо описанных постмодернистских механизмов игрового языкового повтора обратим внимание на то, что анализируемые тексты являются порождением одновременно и постфигуративной, и префигуративной культур, основания которых описаны в работах М. Мид (Mead, 2012). В самых общих чертах постфигуративная культура предполагает передачу опыта от старших младшим, а префигуративная культура это ситуация, когда старшие учатся у молодых. В рамках постфигуративной коммуникации в данном случае мы имеем дело с коммуникативными микротекстами, пришедшими из прошлого и манифестирующими связь поколений в рамках социокодов. Вслед за М. К. Петровым мы употребляем термин «соииокод», «понимая под ним основную знаковую реалию культуры, удерживающую в целостности и различении фрагментированный массив знания, расчлененный на интерьеры мир деятельности и обеспечивающие институты общения» (Петров, 2004: 39). Мы полагаем, что анализируемые повторяемые культурные микротексты следует понимать как единииу социокода. В лингвистике подобные тексты относят к разделу фразеологии. Роль фразеологии в осуществлении связи между поколениями в рамках действующего социокода представлена на рисунке.

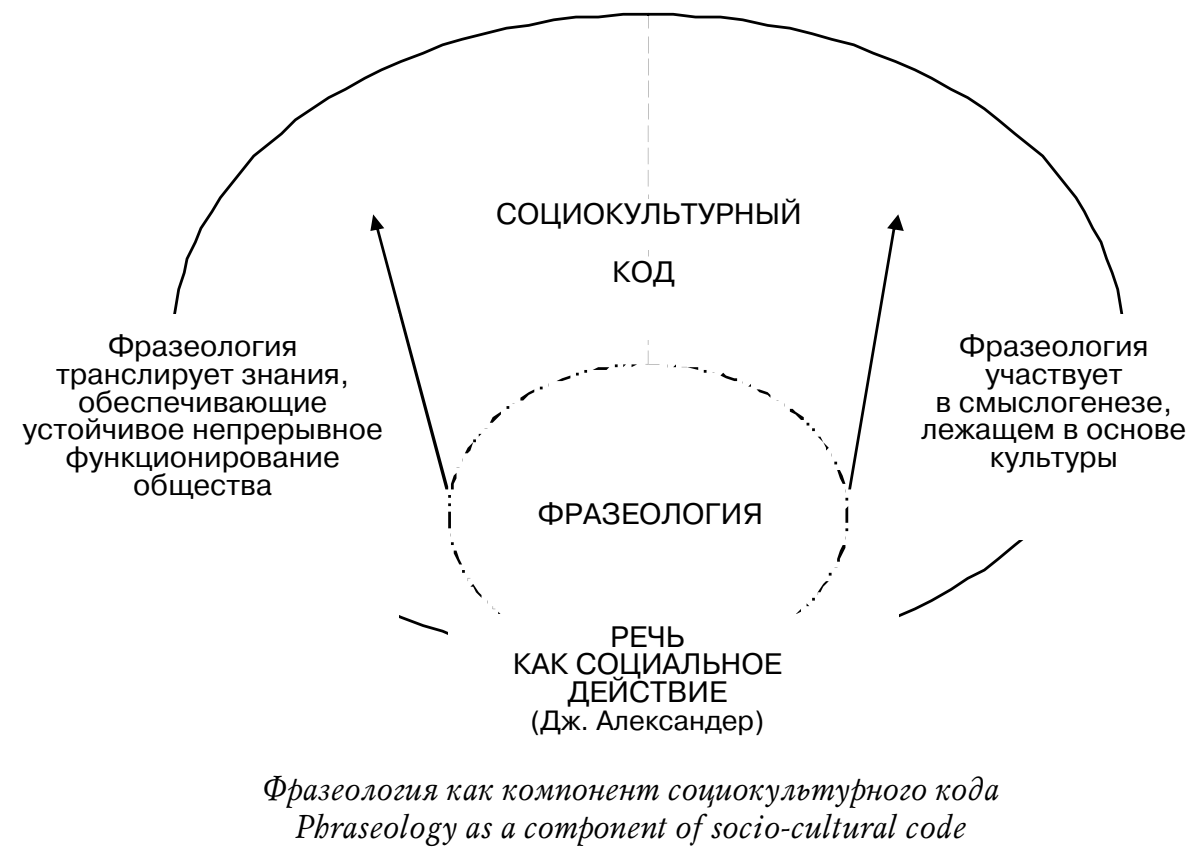

Заметим, что понятия «фразеология», «фразеологическая единица» в лингвистике так и не получили прочных категориальных оснований, ориентируясь на которые стало бы возможно отграничить фразеологизм от не-фразеологизма. Обратимся к мнению авторитетного современного лингвиста Е. В. Рахилиной, которая четко обозначает проблему размытости границ фразеофондов: «Одни лингвисты включают в объект (фразеологии. - H. 3.) только устойчивые сочетания слов, другие - любые 
сочетания слов. На первый взгляд второй подход не отвечает распространенному представлению о фразеологических единицах и поэтому от его рассмотрения сразу же следует отказаться. Однако не стоит делать поспешных выводов. Аело в том, что любые сочетания слов не лишены тех или иных ограничений в своих синтагматических связях. Разве нет таких ограничений у компонентов словосочетаний красное солние или круглая Земля? Ведь нельзя сказать зеленое солние или квадратная Земля. К тому же эти словосочетания, однажды услышанные, повторяются (воспроизводятся) в нашей речи. Как же в таком случае быть с предметом фразеологии? Его нельзя расширять до бесконечности, иначе сама фразеология как наука рискует раствориться в безбрежном пространстве языковых явлений. Очевидно, речь должна идти о $х a-$ рактере тех или иных ограничений в сочетаемости слов в сопряжении с их семантическими свойствами и поведением в речи. Справедливости ради нужно отметить, что и среди сторонников первого подхода также нет полного согласия» (Рахилина, 2010: 245). Развивая высказанную Е. В. Рахилиной мысль о характере ограничений в сочетаемости единиц, мы пришли к выводу о том, что эти ограничения следует искать в зоне сочиокультурного пространства и культурной памяти (по Ю. М. Аотману), а не языка.

Анализируемые микротексты-фразеологизмы существует в тесной связи с эпохой в памяти поколений, по аналогии с артефактами. В 2006 г. в Москве в Музее Московского Кремля состоялась выставка «Аары вождям», на которой были представлены подарки советским вождям (от В. И. Аенина до М. С. Горбачева). Куратор выставки Н. Ссорин-Чайков в своей статье, посвященной выставке, анализирует записи в книге отзывов посетителей выставки (Ssorin-Chaikov, 2013). В отзывах находим многочисленные микротексты-штампы, характерные для эпохи СССР: «The state was giving us the opportunity to implement Lenin's slogan, 'Study, study and one more time study" ( «Государство давало нам возможность осуществить девиз Аенина "Учиться, учиться и еще раз учиться”»)' (там же: 180); «...thanking the state and Stalin for 'our bappy childbood' and 'bappy life' ( «Спасибо товарищу Сталину за “наше счастливое детство" и “счастливую жизнь"») (там же: 182). Ааже кратковременное предъявление предметов ушедшей эпохи вызвало бурный всплеск микротекстовых идиоматических реакций.

Описанное свойство культурных микротекстов-шаблонов - долго храниться в памяти представителей разных поколений - было умело использовано организаторами церемонии открытия Олимпиады в Сочи в 2014 г. На кадрах с церемонии открытия перед зрителями проплывали многочисленные микротексты-шаблоны из прошлых эпох: «У кого что, а у нас свадьба!», «Аети - наше будущее!» (Церемония открытия ... , 2014: Электронный ресурс). В то же время в данном случае мы можем говорить о том, что анализируемые единицы социокода, задействованные в әлектронной коммуникативной среде, в рамках концепции префигуративной культуры представляют собой темы для образовательных программ, которые молодые специалисты предлагают современной публике. Аостаточно обратиться к многочисленным рекомендациям молодых медиаэкспертов, описывающих особенности современной коммуникации в интернет-пространстве (Завьялова, 2015).

\section{ЗАКАЮЧЕНИЕ}

Сформулируем основные выводы. Анализируемые микротексты являются продуктами механизма повтора, лежащего в основе онто-филогенеза и культурогенеза, сле- 
довательно, они обнаруживают глубочайшую связь с основами мироздания. Повторяемые культурные микротексты перспективно рассматривать как единицы социокодов общества. Традиционно данные микротексты являются объектом изучения лингвистики в разделе по фразеологии, однако мы полагаем, что данные микротексты обладают мощнейшим зарядом культурфилософской информации, манифестирующей различные пласты культуры. Анализ результатов всероссийских омнибусных соцопросов выявил довольно высокий процент респондентов, использующих данные обороты в повседневной коммуникации. Анализируемые микротексты задействованы в нескольких культурных моделях одновременно: постфигуративной и префигуративной. Они активно востребованы в постмодернистских игровых техниках, что делает их важнейшим элементом современной электронной коммуникации.

\section{ПРИМЕЧАНИЕ}

1 «То, что произошло раньше, наиболее важно для культурного процесса кодирования, оценивания и повествования».

\section{СПИСОК АИТЕРАТУРЫ}

Афанасьева, Ю. (2015) А рынок, такой молодой! И чудный Сургут впереди! // WhoTrades. Социальная сеть для трейдеров. 20 января [Электронный ресурс]. URL: https://afanaseva.whotrades.com/blog/43002802686 (дата обращения: 25.02.2016).

Барт, Р. (1994) Смерть автора // Барт, Р. Избр. работы. Семиотика. Поэтика / сост., общ. ред. и вступ. ст. Г. К. Косикова. М. : Прогресс-Универс. 616 с. С. 287-305.

Бизнес-тренинг. 28 апреля. 50 оттенков «дорого». Техники предотвращения и преодоления возражений [Электронный ресурс]// Борис Жалило. Катализатор развития. URL: http://conf. expoforum.ru/50-ottenkov-dorogo (дата обращения: 12.03.2016).

Бодрийяр, Ж. (1995) Система вещей / пер. с франц. С. Н. Зенкина. М. : Рудомино ВГБИА им. М. И. Рудомино. 224 с.

Бурлакова, А. (2013) В Москве появились «человек зазаборный» и «царь зверей» [Электронный ресурс]// MK.RU. 4 апреля. URL: http://www.mk.ru/moscow/2013/04/04/836805-v-moskvepoyavilis-chelovek-zazabornyiy-i-tsar-dverey.html (дата обращения: 05.04.2013).

Аокинз, Р. (2015) Рассказ предка. Паломничество к истокам жизни / пер. с англ. С. Аолотовской. М. : АCT ; CORPUS. 768 с.

Завьялова, Н. А. (2014) Механизмы тезаурусного расширения в русле теоретико-информационного подхода как отражение социокультурной динамики // Знание. Понимание. Умение. № 1. C. 194-204.

Завьялова, Н. А. (2015) Культурные коммуникативные универсалии как современный этап развития культуры // Знание. Понимание. Умение. № 1. С. 77-88. DOI: 10.17805/zpu.2015.1.7

Кондратьев, Н. А. (1989) Большие циклы экономической конъюнктуры // Кондратьев, Н. А. Проблемы экономической динамики. М. : Экономика. 523 с. С. 172-226.

Кураев, А., диакон (2006) Церковь и театр. Аитература, история кинематограф// Православие и мир [Электронный ресурс]. URL: http://www.pravmir.ru/stat-content/sc_printer_1253.html (дата обращения: 14.02.2016).

Иелеко, В. А. (2002) Пространство повседневности в европейской культуре. СПб. : СанктПетербург. гос. ун-т культуры и искусств. 320 с.

Ииотар, Ж.-Ф. (1998) Состояние постмодерна / пер. с фр. Н. А. Шматко М. : Ин-т эксперимент. социологии ; СПб. : Алетея. 160 с.

Иотман, Ю. М. (1992) Избр. статьи : в 3 т. Таллин : Александра. Т. 1. Статьи по семиотике и типологии культуры. 475 с.

Ауков, В. А., Ауков, Вл. А. (2013) Тезаурусы II: Тезаурусный подход к пониманию человека и его мира. М. : ИзА-во Нац. ин-та бизнеса. 640 с. 
Аукьянов, Ф. (2013а) Аальний Восток становится ближним [Электронный ресурс]// Россия в глобальной политике. 11 декабря. URL: http://www.globalaffairs.ru/redcol/Dalnii-Vostokstanovitsya-blizhnim-16239 (дата обращения: 11.12.2013).

Аукьянов, Ф. (2013b) Европейцы в поисках «своего угла»: откуда берется стремление жителей ЕС к независимости? // Радио «Голос России». [Электронный ресурc]. URL: https://www. youtube.com/watch?v=eTiD3nJ6VQY (дата обращения: 07.12.2013).

Механик, А. (2015) Униженные и оскорбленные современного мира [Электронный ресурс]// Эксперт Online. 22 мая. URL: http://expert.ru/expert/2015/01/unizhennyie-i-oskorblennyie-sovremennogo-mira/ (дата обращения 10.09.2015).

Одайник, В. (1996) Психология политики: Политические и социальные идеи Карла Густава Юнга / пер. с англ. К. Бутырина. СПб. : Ювента. 381 с.

Орлова, Э. А. (2010) История антропологических учений : учебник для студентов пед. вузов. М. : Академический Проект ; Альма Матер. 621 с.

Парабеллум, А., Мрочковский, Н. (2011) Выжми из бизнеса все! 200 способов повысить продажи и прибыль. СПб. : Питер. 192 с.

Парабеллум, А., Мрочковский,Н. (2012) Бизнес без правил. Как разрушать стереотипы и получать сверхприбыль. СПб. : Питер. 192 с.

Петров, М. К. (2004) Язык, знак, культура / вступ. ст. С. С. Неретиной. 2-е изд., стер. М. : Едиториал УРСС. 328 с.

Рахилина, Е. В. (2010) Когнитивный анализ предметных имен: семантика и сочетаемость. 2-е изА., испр. и доп. М. : Азбуковник. 448 с.

Родионов, А. (2015) Возвращение блудного Януковича. Клан бывшего президента Украины ищет возможности для реванша [Электронный ресурс] // Свободная Пресса. 8 января. URL: http://svpressa.ru/politic/article/109332/ (дата обращения: 14.11.2015).

Филмер, П. (1978) Об этнометодологии Гарольда Гарфинкеля // Новые направления в социологической теории / общ. ред. Г. В. Осипова. М. : Прогресс. 392 с. С. 328-375.

Церемония открытия Олимпийских игр в Сочи 2014 года [Электронный ресурс] // Yutube.com. URL: https://www.youtube.com/watch?v=ISAPRR_yTHg (дата обращения: 14.11.2015).

«Чем бы дитя ни тешилось...» Геи выходят на митинг у «Останкино». А все из-за Мамонтова и Челябинского метеорита. ВИАЕО (2013) [Электронный ресурс] // URA.RU. URL: http:// ura.ru/news/1052169048 (дата обращения: 14.12.2015).

Юнг, К. Г. (2010) Очерки по психологии бессознательного. М. : Когито-Центр. 352 с.

Alexander, C. J. (2003) The Meanings of Social Life: A Cultural Sociology. Oxford University Press. 296 p.

Fang, X., Singh, S., Ahluwalia, R. (2007) An Examination of Different Explanations for the Mere Exposure Effect // Journal of Consumer Research. Vol. 34. P. 97-103.

Fombrun, Ch., Shanley, M. (1990) What's in a Name? Reputation Building and Corporate Strategy // Academy of Management Journal. Vol. 33 (2). P. 233-258. DOI: 10.2307/256324

Jacoby, L. L., Dallas, M. (1981) On the relationship between autobiographical memory and perceptual learning // Journal of Experimental Psychology: General. Vol. 110 (3). P. 306-340. DOI:10.1037/0096-3445.110.3.306

Mead, M. (2012) Continities in Cultural Evolution. Transaction Publishers. 471 p.

Reber, R., Winkielman, P., Schwarz, N. (1998) Effects of Perceptual Fluency on Affective Judgments // Psychological Science. Vol. 9 (1). P. 45-48. DOI: 10.1111/1467-9280.00008

Ssorin-Chaikov, N. (2013) Gift/Knowledge Relations at the Exhibition of Gifts to Soviet Leaders // Laboratorium: Russian Review of Social Research. Vol. 5 (2). \# 2. P. 166-192.

Twain, M. (1972) Fables of Man. University of California Press. 741 p.

Zajonc, R. B. (2001) Mere Exposure: A Gateway to the Subliminal// Current Directions in Psychological Science. Vol. 10 (6). P. 224-228. DOI:10.1111/1467-8721.00154 


\section{REPEATED CULTURAL MICROTEXTS: DIACHRONIC AND SYNCRONIC APPROACHES \\ N. A. ZAVYALOVA}

(URAL Federal University named AfTER the FIRST PRESIDENT of Russia B. N. YeltSin)

The article is a result of a research programme of studying repeated cultural microtexts. The article focuses on the items which traditionally lie within the domain of modern linguistics. However, traditional linguistics has failed to offer strict criteria which make it possible to differentiate between the units under analysis and the units which fall under similar, yet different categories. Building on the works by Yu. M. Lotman, Val. A. Lukov and Vl. A. Lukov, the author makes an attempt to offer a new set of criteria which belong to the domain of cultural philosophy and anthropology.

The basic demarcation line between the phenomena under analysis and others may be drawn along the lines of superunity of cultural meanings (Yu. M. Lotman) and a large number of repetitions, made by native speakers both in oral and written speech. The microtexts are based on the copying (repetition) mechanism, which lies at the heart of universal laws, ranging from DNA to microeconomic cycles.

The article is also based on omnibus survey results obtained through the collaboration with the Yu. Levada centre in 2014 and 2016 (number of respondents: 1600+). The survey convincingly proved a largescale use of microtexts in everyday communication. The microtexts can also be viewed as the elements of postfigurative and prefigurative cultures as suggested by M. Mead. They are an integral part of modern electronic mass media, advertising and on-line communication. Our theoretical conclusions are supported by a large number of examples from advertising, mass media and reports on cultural events, including the opening ceremony of the 2014 Olympics in Sochi.

The phenomenon of microtexts can be studied by means of a mixture of anthropological, cultural, philosophical and linguistic analysis. This approach makes it possible to describe the results as ones of multidisciplinary importance.

Keywords: repetition; copy; text; repeated texts; thesaurus; thesaurus approach; sociocultural space; cultural microtexts; synchronous; diachronic

\section{REFERENCES}

Afanas'eva, Yu. (2015) A rynok, takoi molodoi! I chudnyi Surgut vperedi! [The market, so young and wonderful, and Surgut in the lead] WhoTrades. Sotsial'naia set' dlia treiderov. January 20 [online] Available at: https://afanaseva.whotrades.com/blog/43002802686 (access date: 25.02.2016). (In Russ.).

Barthes, R. (1994) Smert' avtora [The death of the author]. In: Barthes, R. Izbrannye raboty. Semiotika. Poetika [Selected works. Semiotics. Poetics], ed. G. K. Kosikova. Moscow, Progress-Univers Publ. 616 p. Pp. 287-305. (In Russ.).

Biznes-trening. 28 aprelia. 50 ottenkov «dorogo». Tekhniki predotvrashcheniia i preodoleniia vozrazhenii [Business training. April 28. 50 shades of expensive. Tecnhiques of preventing and overcoming contradictions]. Boris Zhalilo. Katalizator razvitiia [online] Available at: http://conf.expoforum.ru/50-ottenkov-dorogo (access date: 12.03.2016). (In Russ.).

Baudrillard, J. (1995) Sistema veshchei [The system of objects], tr. S. N. Zenkin. Moscow, Rudomino Publ. 224 p. (In Russ.).

Burlakova, D. (2013) V Moskve poiavilis' «chelovek zazabornyi» i «tsar' zverei» [Moscow now has 'the man from behind the fence' and 'the tsar of animals']. MK.RU, April 4 [online] Available at: http://www.mk.ru/moscow/2013/04/04/836805-v-moskve-poyavilis-chelovek-zazabornyiy-i-tsardverey.html (access date: 05.04.2013). (In Russ.).

Dawkins, R. (2015) Rasskaz predka. Palomnichestvo $k$ istokam zhizni [The Ancestor's Tale: A Pilgrimage to the Dawn of Life], ed. S. Dolotovskaia. Moscow, AST ; CORPUS Publ. 768 p. (In Russ.).

Zavyalova, N. A. (2014) Mekhanizmy tezaurusnogo rasshireniia v rusle teoretiko-informatsionnogo podkhoda kak otrazhenie sotsiokul'turnoi dinamiki [The Mechanisms of Thesaurus Expansion within the Framework of the Information-theoretic Approach as a Reflection of Socio-Cultural Dynamics]. Znanie. Ponimanie. Umenie, no. 1, pp. 194-204. (In Russ.). 
Zavyalova, N. A. (2015) Kul'turnye kommunikativnye universalii kak sovremennyi etap razvitiia kul'tury [Cultural communicative formulae as the current stage of culture genesis]. Znanie. Ponimanie. Umenie, no. 1, pp. 77-88. DOI: 10.17805/zpu.2015.1.7 (In Russ.).

Kondrat'ev, N. D. (1989) Bol'shie tsikly ekonomicheskoi kon»iunktury [Long-term cycles of economy]. In: Kondrat'ev, N. D. Problemy ekonomicheskoi dinamiki [Problems of economic dynamics]. Moscow, Ekonomika Publ. 523 p. Pp. 172-226. (In Russ.).

Kuraev, A., diakon (2006) Tserkov' i teatr. Literatura, istoriia, kinematograf [The church and theatre. Literature, history and cinematography]. Pravoslavie $i$ mir [online] Available at: http://www. pravmir.ru/stat-content/sc_printer_1253.html (access date: 14.02.2016). (In Russ.).

Leleko, V. D. (2002) Prostranstvo povsednevnosti v evropeiskoi kul'ture [The space of the everyday in European culture]. Saint Petersburg, Petersburg State University of Culture and Fine Arts Publ. 320 p. (In Russ.).

Lyotard, J.-F. (1998) Sostoianie postmoderna [The postmodern condition], tr. N. A. Shmatko Moscow, Institute for experimental sociology; Saint Petersburg, Aleteiia Publ. 160 p. (In Russ.).

Lotman, Yu. M. (1992) Izbrannye stat' $i$ [Selected articles]: in 3 vols. Tallinn, Aleksandra Publ. Vol. 1. Stat' $i$ po semiotike $i$ tipologii kul'tury [Articles on semiotics and typology of culture]. $475 \mathrm{p}$. (In Russ.).

Lukov, V. A. and Lukov, Vl. A. (2013) Tezaurusy II: Tezaurusnyi podkbod k ponimaniiu cheloveka $i$ ego mira [Thesauri II: The thesaurus approach to the conceptualization of the person and his/her World]. Moscow, National Institute of Business Publ. 640 p. (In Russ.).

Luk'ianov, F. (2013a) Dal'nii Vostok stanovitsia blizhnim [The Far East getting near]. Rossiia $v$ global' noi politike, December 11 [online] Available at: http://www.globalaffairs.ru/redcol/DalniiVostok-stanovitsya-blizhnim-16239 (access date: 11.12.2013). (In Russ.).

Luk'ianov, F. (2013b) Evropeitsy v poiskakh «svoego ugla»: otkuda beretsia stremlenie zhitelei ES $\mathrm{k}$ nezavisimosti? [Europeans in search for 'a corner of their own': Whence the EU drive for independence?]. Radio Golos Rossii [online] Available at: https://www.youtube.com/watch?v=eTiD3nJ6VQY (access date: 07.12.2013). (In Russ.).

Mekhanik, A. (2015) Unizhennye i oskorblennye sovremennogo mira [The humiliated and insulted of the contemporary world]. Ekspert Online. May 22. [online] Available at: http://expert.ru/ expert/2015/01/unizhennyie-i-oskorblennyie-sovremennogo-mira/ (access date 10.09.2015). (In Russ.).

Odajnyk, W. (1996) Psikbologiia politiki: Politicheskie i sotsial'nye idei Karla Gustava Iunga [Jung and Politics: The Political and Social Ideas of C. G. Jung], tr. K. Butyrin. Saint Petersburg, Iuventa Publ. 381 p. (In Russ.).

Orlova, E. A. (2010) Istoriia antropologicheskikb uchenii : uchebnik dlia studentov ped. vuzov [History of anthropological theories]. Moscow, Akademicheskii Proekt ; Al'ma Mater Publ. 621 p. (In Russ.).

Parabellum, A., and Mroczkowski, N. (2011) Vyzhmi iz biznesa vse! 200 sposobov povysit' prodazbi i pribyl' [Squeeze business dry! 200 ways to raise sales and profits]. Saint Petersburg, Piter Publ. 192 p. (In Russ.).

Parabellum, A., and Mroczkowski, N. (2012) [Business without rules. How to destroy stereotypes and get superprofits]. Saint Petersburg, Piter Publ. 192 p. (In Russ.).

Petrov, M. K. (2004) Iazyk, znak, kul'tura [Language, sign, culture]. 2nd edn. Moscow, Editorial URSS Publ. 328 p. (In Russ.).

Rakhilina, E. V. (2010) Kognitivnyi analiz predmetnykb imen: semantika $i$ sochetaemost' [Cognitive analysis of object nouns: semantics and combinatorics]. $2^{\text {nd }}$ edn, augm. and exp. Moscow, Azbukovnik Publ. 448 p. (In Russ.).

Rodionov, D. (2015) Vozvrashchenie bludnogo Ianukovicha. Klan byvshego prezidenta Ukrainy ishchet vozmozhnosti dlia revansha [The return of the prodigal Yanukovich. The clan of Ukraine's expresident looking for revenge]. Svobodnaia Pressa. January 8. [online] Available at: http://svpressa.ru/politic/article/109332/ (access date: 14.11.2015). (In Russ.). 
Filmer, P. (1978) Ob etnometodologii Garol'da Garfinkelia [On Harold Garfinkel's Ethnomethodology]. In: Novye napravleniia $v$ sotsiologicheskoi teorii [New directions in sociological theory], ed. G. V. Osipov. Moscow, Progress Publ. 392 p. Pp. 328-375. (In Russ.).

Tseremoniia otkrytiia Olimpiiskikh igr v Sochi 2014 goda [Sochi Olympics 2014: The Opening ceremony]. Youtube.com [online] Available at: https://www.youtube.com/watch?v=ISAPRR_yTHg (access date: 14.11.2015). (In Russ.).

«Chem by ditia ni teshilos'...» Gei vykhodiat na miting u «Ostankino». A vse iz-za Mamontova i Cheliabinskogo meteorita. Video (2013) [Any toy is OK: Gays rally at Ostankino, all because of Mamontov and Chelyabinsk: Video meteorite]. URA.RU [online] Available at: http://ura.ru/news/ 1052169048 (access date: 14.12.2015). (In Russ.).

Jung, K. G. (2010) Ocherki po psikbologii bessoznatel'nogo [Psychology of the Unconscious]. Moscow, Kogito-Tsentr Publ. 352 p. (In Russ.).

Alexander, C. J. (2003) The Meanings of Social Life: A Cultural Sociology. Oxford University Press. 296 p.

Fang, X., Singh, S., and Ahluwalia, R. (2007) An Examination of Different Explanations for the Mere Exposure Effect. Journal of Consumer Research, vol. 34, pp. 97-103.

Fombrun, Ch., and Shanley, M. (1990) What's in a Name? Reputation Building and Corporate Strategy. Academy of Management Journal, vol. 33 (2), pp. 233-258. DOI: 10.2307/256324

Jacoby, L. L., and Dallas, M. (1981) On the relationship between autobiographical memory and perceptual learning. Journal of Experimental Psychology: General, vol. 110 (3), pp. 306-340. DOI:10.1037/0096-3445.110.3.306

Mead, M. (2012) Continities in Cultural Evolution. Transaction Publishers. 471 p.

Reber, R., Winkielman, P., and Schwarz, N. (1998) Effects of Perceptual Fluency on Affective Judgments. Psychological Science, vol. 9 (1), pp. 45-48. DOI: 10.1111/1467-9280.00008

Ssorin-Chaikov, N. (2013) Gift/Knowledge Relations at the Exhibition of Gifts to Soviet Leaders. Laboratorium: Russian Review of Social Research, vol. 5 (2), no. 2, pp. 166-192.

Twain, M. (1972) Fables of Man. University of California Press. 741 p.

Zajonc, R. B. (2001) Mere Exposure: A Gateway to the Subliminal. Current Directions in Psychological Science, vol. 10 (6), pp. 224-228. DOI:10.1111/1467-8721.00154

Submission data: 15.03.2016.

Завьялова Наталья Алексеевна - кандидат филологических наук, доцент, доцент Уральского федерального университета им. первого Президента России Б. Н. Ельцина, докторант кафедры социологии Московского гуманитарного университета. Адрес: 620002, Россия, г. Екатеринбург, ул. Мира, д. 19. Тел.: +7 (343) 375-44-44. Эл. aдpec: N.A.Zavialova@urfu.ru

Zavyalova Natalya Alekseevna, Candidate of Philology, Associate Professor, Ural Federal University named after the first President of Russia B. N. Yeltsin; Doctoral Researcher, Department of Sociology, Moscow University for the Humanities. Postal address: 19 Mira Str., Yekaterinburg, Russian Federation 620002. Tel.: +7 (343) 375-44-44.E-mail: N.A.Zavialova@urfu.ru 